\title{
Prevalence and associated factors of developing venous thromboembolism in the perioperative period
}

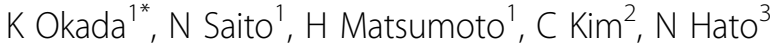 \\ From ESICM LIVES 2015 \\ Berlin, Germany. 3-7 October 2015
}

\begin{abstract}
Intr
Previous studies suggested that the prevalence of venous thromboembolism (VTE) is considerably lower in Asian populations compared with Western populations. It is therefore indicated that the incidence and risk of developing VTE among Asian countries should be evaluated separately.
\end{abstract}

\section{Objectives}

This study aimed to clarify the epidemiology and associated factors of developing VTE during the perioperative period in a tertiary care hospital in Japan.

\section{Methods}

We retrospectively reviewed patients who underwent operation under general anaesthesia between August 2011 and December 2013. VTE in the perioperative period was identified through contrast enhanced $\mathrm{CT}$ which was performed from 30 days before operations until 90 days after operations. Multivariate logistic regression was conducted to assess the associated factors of developing VTE.

\section{Results}

8287 patients were included in this analysis. The mean age of subjects was $58.7 \pm 16.5$ years and there were $3973(47.9 \%)$ female patients. $102(1.23 \%)$ cases showed the evidence of VTE during the period and 64 were diagnosed postoperatively. Of these, 34 (53\%) patients received pharmacological prophylaxis after operation. In-hospital mortality of patients with VTE was 3.9\%. Multivariate analysis revealed that associated factors of developing VTE were female patients (odds ratio [OR] $3.24,95 \%$ confidence interval $[\mathrm{CI}] 1.84$ to $5.70, \mathrm{P}<$ 0.001 ), receiving open reduction internal fixation (ORIF) (OR 2.96, 95\%CI 1.49 to $5.88, \mathrm{P}=0.002$ ), and receiving multiple surgeries during the course of hospitalization (OR 32.25, 95\%CI 18.21 to $57.11, \mathrm{P}<0.001$ ).

\section{Conclusions}

The perioperative incidence of VTE was substantially lower in this study than in previous reports for Western populations. Patients who were female, had ORIF and multiple surgeries were highly associated with the occurrence of VTE.

\section{Authors' details}

${ }^{1}$ Nippon Medical School, Shock and Trauma Center, Inzai, Japan. ${ }^{2}$ Nippon Medical School, Department of Anesthesiology, Inzai, Japan. ${ }^{3}$ Nippon Medical School, Division of Intensive Care Unit, Inzai, Japan.

Published: 1 October 2015

\section{References}

1. Cohen AT, Tapson VF, Bergmann JF, et al: Venous thromboembolism risk and prophylaxis in the acute hospital care setting (ENDORSE study): a multinational cross-sectional study. Lancet 2008, 371:387-94.

2. Kunisawa S, Ikai H, Imanaka $Y$ : Incidence and prevention of postoperative venous thromboembolism: are they meaningful quality indicators in Japanese health care settings? World J Surg 2012, 36:280-6.

3. Geerts $W H$, Bergqvist $D$, Pineo GF, et al: Prevention of venous thromboembolism: American College of Chest Physicians evidencebased clinical practice guildelines (8th edition). Chest 2008, 133:381S-453S.

doi:10.1186/2197-425X-3-S1-A231

Cite this article as: Okada et al.: Prevalence and associated factors of developing venous thromboembolism in the perioperative period. Intensive Care Medicine Experimental 2015 3(Suppl 1):A231. 